\title{
Cardiovascular Problems in the Fragile X Premutation
}

\author{
Nattaporn Tassanakijpanich ${ }^{1,2}$, Jonathan Cohen ${ }^{3}$, Rashelle Cohen ${ }^{3}$, Uma N. Srivatsa ${ }^{4}$ \\ and Randi J. Hagerman ${ }^{1,5 *}$ \\ ${ }^{1}$ UC Davis MIND Institute, UC Davis Health, Sacramento, CA, United States, ${ }^{2}$ Department of Pediatrics, Faculty \\ of Medicine, Prince of Songkla University, Songkhla, Thailand, ${ }^{3}$ Fragile X Alliance Clinic, Genetic Clinics Australia, Melbourne, \\ VIC, Australia, ${ }^{4}$ Division of Cardiovascular Medicine, Department of Internal Medicine, UC Davis Medical Center, \\ Sacramento, CA, United States, ${ }^{5}$ Department of Pediatrics, University of California, Davis, Davis, School of Medicine, \\ Sacramento, CA, United States
}

\section{OPEN ACCESS}

Edited by:

Renate K. Hukema,

Rotterdam University of Applied

Sciences, Netherlands

Reviewed by:

Rita Selvatici,

University of Ferrara, Italy

Charlotte L. Alston,

Wellcome Trust Centre

for Mitochondrial Research (WT),

United Kingdom

*Correspondence:

Randi J. Hagerman

rihagerman@ucdavis.edu

Specialty section:

This article was submitted to Genetics of Common and Rare

Diseases,

a section of the journal

Frontiers in Genetics

Received: 24 July 2020

Accepted: 21 September 2020

Published: 08 October 2020

Citation:

Tassanakijpanich N, Cohen J,

Cohen R, Srivatsa UN and

Hagerman RJ (2020) Cardiovascular

Problems in the Fragile $X$ Premutation.

Front. Genet. 11:586910.

doi: 10.3389/fgene.2020.586910
There is a dearth of information about cardiovascular problems in fragile $X$ premutation carriers who have 55-200 CGG repeats in fragile X mental retardation 1 (FMR1) gene. The FMR1 expansion in the premutation range leads to toxic RNA gain-of-function resulting in cellular dysregulation. The mechanism of RNA toxicity underlies all of the premutation disorders including fragile $X$-associated tremor/ataxia syndrome, fragile $X$-associated primary ovarian insufficiency, and fragile $X$-associated neuropsychiatric disorder. Cardiovascular problems particularly autonomic dysfunction, hypertension, and cardiac arrhythmias are not uncommon in premutation carriers. Some arterial problems and valvular heart diseases have also been reported. This article reviews cardiovascular problems in premutation carriers and discusses possible contributing mechanisms including RNA toxicity and mild fragile $X$ mental retardation protein deficiency. Further research studies are needed in order to prove a direct association of the cardiovascular problems in fragile $X$ premutation carriers because such knowledge will lead to better preventative treatment.

Keywords: fragile X, FMR1, premutation, cardiovascular, arrhythmia, autonomic dysfunction, hypertension

\section{INTRODUCTION}

The Fragile X Mental Retardation 1 (FMR1) gene is located at Xq27.3 and the $5^{\prime}$-untranslated region contains a trinucleotide repeat of cytosine-guanine-guanine (CGG), that has a normal range of 5 to 45 repeats with a mean of 30 in the general population. The full mutation of the FMR1 gene contains $>200$ CGG repeats and this causes fragile X syndrome (FXS), the most common inherited cause of intellectual disability and the most common single gene cause of autism spectrum disorder. This condition leads to silencing of FMR1 gene by methylation and subsequent loss of its product,

Abbreviations: ADHD, Attention-deficit/hyperactivity disorder; CGG, Cytosine-guanine-guanine; FMR1, Fragile X mental retardation 1; FMRP, Fragile X mental retardation protein; FXAND, Fragile X-associated neuropsychiatric disorders; FXPOI, Fragile X-associated primary ovarian insufficiency; FXS, Fragile X syndrome; FXTAS, Fragile X-associated tremor/ataxia syndrome; MMP, Matrix metalloproteinase; MRI, Magnetic resonance imaging; mRNA, Messenger RNA; SCAD, Spontaneous coronary artery dissection; SD, Standard deviation. 
fragile $\mathrm{X}$ mental retardation protein (FMRP). FMRP is a messenger RNA (mRNA)-binding protein and regulates translation at the synapse of hundreds of mRNAs essential for synaptic plasticity. Therefore, its absence leads to significant cognitive and social impairment (Hagerman et al., 2017; Rajaratnam et al., 2017).

Moreover, cardiovascular problems including mitral valve prolapse, aortic root dilatation, and hypertension are commonly documented in individuals with FXS (Loehr et al., 1986; Waldstein and Hagerman, 1988; Sreeram et al., 1989; Utari et al., 2010; Ramírez-Cheyne et al., 2019). These problems were explained as a result of diminished or absent FMRP which leads to abnormal connective tissue structures including shortened and fragmented elastin fibers. However, cardiovascular conditions in premutation carriers, who have 55-200 CGG repeats on FMR1 gene, are still rarely recognized except in occasional case studies (Riddle et al., 1998; Jacquemont et al., 2003; Coffey et al., 2008; Chonchaiya et al., 2010; Hunsaker et al., 2011; Hamlin et al., 2012). Since the premutation is common, 1 per 200 in women and 1 per 400 in men (Tassone et al., 2012b), the cardiovascular problems which can occur in carriers are relatively common. Our aim in this review is to advance understanding about possible risks and mechanisms of cardiovascular disorders in premutation carriers which will hopefully stimulate further research and treatment studies.

\section{THE FRAGILE X PREMUTATION}

Unlike individuals with FXS who usually have remarkable clinical features including intellectual disability, autism spectrum disorder, macroorchidism, hyperactivity, prominent ears, and hyperextensible finger joints, the premutation carriers have subtle presentations. Medical problems which are increased in carriers compared to controls without the premutation include autoimmune diseases (Winarni et al., 2012), premature menopause before age 40 and fertility problems (fragile $\mathrm{X}$-associated primary ovarian insufficiency; FXPOI) (Wheeler et al., 2014; Campbell et al., 2016), and the neurodegenerative disorder involving an intention tremor, ataxia and cognitive decline later in life called the fragile $\mathrm{X}$-associated tremor/ataxia syndrome (FXTAS) (Jacquemont et al., 2004; Hagerman and Hagerman, 2016). FXPOI is seen in approximately $20 \%$ of female carriers and FXTAS is seen in $40 \%$ of male carriers and approximately $13 \%$ of female carriers. In addition, psychiatric problems are common, particularly anxiety, depression, obsessive-compulsive disorder, mood disorder, and they fall under the umbrella term of fragile $\mathrm{X}$-associated neuropsychiatric disorders (FXAND). One or more of these psychiatric problems can affect up to $50 \%$ of carriers (Wheeler et al., 2014; Hagerman et al., 2018).

Cardiovascular problems in premutation carriers have been documented but most cases were mentioned indirectly as a part of case studies or reviews about FXTAS. Here we present case histories of three carriers who had significant cardiovascular conditions along with a review of the literature of each condition in carriers.

\section{CASE PRESENTATION}

\section{Case 1}

A 61-year-old female with a FMR1 premutation allele of 76 CGG repeats who is physically active. She has two children with FXS, so they were the initial probands. Her father also had FXTAS and he had ischemic heart disease. She has hyperextensible joints and recurrent knee dislocation with skiing. She had a 4 year history of paroxysmal atrial fibrillation largely controlled with sotalol hydrochloride $40 \mathrm{mg}$ twice daily. Whilst not aware of palpitations, she did note exertional breathlessness and slight limitation of her physical activity. She also noted pre-syncopal symptoms related to conversion pauses which would occur on average 2-3 times per week. Holter electrocardiogram monitoring confirmed her to have paroxysmal episodes of atrial fibrillation up to $7 \mathrm{~h}$ at a time, with significant conversion pauses of up to $2.3 \mathrm{~s}$ in length. This also demonstrated periods of rapid ventricular response with up to $130 \mathrm{bpm}$. Her exercise thallium scan result was normal, and her echocardiogram and cardiac computer tomography revealed trivial pericardial effusion. Laboratory panel results were unremarkable. Medications included atorvastatin $40 \mathrm{mg}$ daily, aspirin $100 \mathrm{mg}$ daily, sotalol hydrochloride $40 \mathrm{mg}$ twice daily, denosumab $60 \mathrm{mg}$ twice yearly.

Physical examination showed normal vital signs although often with an irregular pulse consistent with atrial fibrillation. Aside from a narrow face and slightly protuberant ears, there were no other stigmata associated with her fragile $\mathrm{X}$ premutation of 76 CGG repeats. Cardiovascular examination was normal.

Primarily in view of her symptomatic conversion pauses and refractoriness and intolerance to higher doses of medications, pulmonary vein isolation and atrial ablation were successfully performed. She remained in sinus rhythm and was discharged home on sotalol $40 \mathrm{mg}$ twice daily and dabigatran $110 \mathrm{mg}$ twice daily for 2 months and is followed in cardiology clinic.

\section{Review of Literature: Cardiac Arrhythmia in the Premutation}

Cardiac arrhythmia is not uncommon in premutation carriers especially in those who have FXTAS. Characteristics include atrial fibrillation (Greco et al., 2006), sick sinus syndrome (Greco et al., 2006), and unspecified cardiac arrhythmia (Hunsaker et al., 2011; Tassone et al., 2012a) have been reported. Many carriers who are elderly have significant bradycardia or other arrhythmia which requires a pacemaker (Greco et al., 2006; Hunsaker et al., 2011; Tassone et al., 2012a). There is only a rare report of arrhythmias in carriers without FXTAS including one case of a 7-years 6-month-old boy with an unmethylated 58 CGG repeats on FMR1 gene who had multiple premature ventricular contractions (Tassone et al., 2000b). However, no direct study about cardiac arrhythmia in carriers of the premutation has been published.

\section{Case 2}

Case 2 is a 60 -year-old female with a FMR 1 premutation allele of 73 CGG repeats. Her father passed away at the age of 79 from FXTAS and congestive heart failure. Postural tremor in left 
hand started at age 49 followed by handwriting and memory problem at age 52 and decrease vibration sense in both feet at age 58. White matter lesions on brain magnetic resonance imaging (MRI) findings were consistent with FXTAS.

Mitral valve prolapse and regurgitation was detected when she was 53 years old. She also had orthostatic hypotension and autonomic instability when she was 57 years old. Hypertension has been noted since age 58. Tricuspid valve regurgitation, smaller left ventricle, and left ventricular outflow tract obstruction were also documented. She takes $25 \mathrm{mg}$ of metoprolol for her cardiac conditions.

\section{Review of Literature: Autonomic Dysfunction in the Premutation}

Autonomic dysfunction is a common problem in the premutation carriers especially with FXTAS and it usually precedes diagnosis of FXTAS (Jacquemont et al., 2003, 2004; Pugliese et al., 2004; Leehey, 2009; Hagerman and Hagerman, 2013). In non-FXTAS carriers, a study found that the premutation females had reduced vagal tone which reflects impaired parasympathetic response (Klusek et al., 2017). In terms of cardiovascular disorders, the clinical presentation of autonomic dysfunction includes episodic hypotension (Pugliese et al., 2004; Greco et al., 2006; Gokden et al., 2009; Hagerman and Hagerman, 2013) and hypertension (Jacquemont et al., 2003; Coffey et al., 2008; Chonchaiya et al., 2010; Hamlin et al., 2012). Hypertension is the only condition which has been studied directly compared to controls and it is increased in carriers particularly those with FXTAS (Coffey et al., 2008; Hamlin et al., 2012).

Hypertension is highly prevalent in the premutation carriers particularly in the carriers with FXTAS. Since the Jacquemont et al. (2003) paper found that $50 \%$ of the premutation males had hypertension, there have been several studies which focused on prevalence of hypertension in premutation carriers. In females, a study found that $16.4 \%$ of premutation females without FXTAS had been diagnosed with hypertension compared with $10.1 \%$ in the age-matched control females (Coffey et al., 2008). The association was significant in females with FXTAS, where $61.1 \%$ had a history of hypertension compared with $18 \%$ of age-match control females (Coffey et al., 2008). In addition, hypertension tended to be more prevalent in premutation females who were daughters of males with FXTAS than the other carriers although there was no statistical significance (18.09 vs. $8.33 \%$, respectively; $p=0.28)$ (Chonchaiya et al., 2010).

In premutation males, the results were consistent with findings in premutation females. A study of Hamlin et al. (2012) found that premutation males age 40 and above had 1.61 higher risk of having hypertension than controls. Their mean systolic blood pressure was 136.73 (SD 14.5) and diastolic blood pressure was 81.45 (SD 7.99) even on hypertensive medication. The risk of having hypertension was significant in the premutation males with FXTAS. They had an odds ratio 3.22 to have hypertension compare with age-matched control males. This study found that $67 \%$ of the premutation males with FXTAS and $41.5 \%$ of the premutation males without FXTAS had hypertension compare with $27.4 \%$ in the control group. Data about age of onset is still inconclusive since it was gathered retrospectively; however, it seemed comparable between the carriers and age-matched controls (Chonchaiya et al., 2010; Hamlin et al., 2012).

\section{Review of Literature: Valvular Heart Disease in the Premutation}

Valvular heart disease including mitral regurgitation and aortic stenosis in premutation carriers have been reported in individuals with FXTAS and some of them needed valvular replacement (Greco et al., 2006; Hunsaker et al., 2011).

\section{Case 3}

A 41-year-old male with a FMR1 premutation allele of 84 CGG repeats presented with a history of early connective tissue problems that included an umbilical hernia at 5 years old, recurrent bilateral muscle tears in the gastrocnemius muscles beginning at age 38 , and spontaneous subluxation of the proximal interphalangeal joint of his right middle finger. Anxiety with panic attacks, migraine headaches, and obstructive sleep apnea has been described in his medical history. His daughter has the premutation and was the proband for the family.

At age 41, he was diagnosed with a dissection of the right upper cervical internal carotid artery extending into the proximal right petrous segment causing $60 \%$ luminal narrowing. He also had the right vertebral arterial dissection at C2 level, measuring $4 \mathrm{~mm}$ and a small left proximal cavernous internal carotid aneurysm. He did not undergo surgical intervention and was treated with aspirin $81 \mathrm{mg}$ per day. Follow-up brain MRI was done 3 months after he was diagnosed which demonstrated significant resolution of the dissection and aneurysm.

\section{Review of Literature: Arterial Dissection and Aneurysm in the Premutation}

This is the first report of internal carotid artery dissection, vertebral artery dissection, and internal carotid aneurysm in the premutation. Similarly, thoracic aortic dissection and abdominal aortic aneurysm have been reported as a cause of death in a 69-year-old male with FXTAS (Gokden et al., 2009). Recently, three premutation females with spontaneous coronary artery dissection (SCAD) who presented with chest pain have been documented (Park et al., 2017; McKenzie et al., 2020). These conditions have shared pathophysiology which is weakening arterial wall integrity from abnormal connective tissue morphology and inflammation (Hashimoto et al., 2006; Dogan et al., 2008; Sadasivan et al., 2013; Hayes et al., 2018; Yetkin and Ozturk, 2018).

\section{DISCUSSION}

We report cases of atrial fibrillation, autonomic dysfunction, and vascular dissection in premutation carriers. To the best of our knowledge, this is the first perspective of cardiovascular problems in association with the fragile $\mathrm{X}$ premutation. We would like to postulate possible mechanisms for such an association: (1) RNA 
toxicity and (2) FMRP deficiency. They both play a role in each condition, but they are not mutually exclusive (Figure 1).

\section{The First Mechanism: RNA Toxicity}

The concept of RNA toxicity has been reviewed extensively in FXTAS (Greco et al., 2006; Hagerman and Hagerman, 2013, 2016). In the premutation range, transcription of FMR1 mRNA is enhanced compared to normal and the FMR1 mRNA levels increase as the CGG repeat increases (Tassone et al., 2000a, 2007; Kenneson et al., 2001). Two mechanisms resulting from excessive mRNA are explained (Hagerman and Hagerman, 2015). The first mechanism is a post-transcriptional mechanism. The elevation of the mRNA sequestrates and binds to RNA binding proteins (i.e., DROSHA, DGCR8, Sam68, and HNRNPA2B1) and the sequestration of DROSHA/DGCR8 down regulates microRNA which are important for maintaining normal cellular functions (Garcia-Arocena and Hagerman, 2010; Sellier et al., 2010, 2013, 2014; Hagerman and Hagerman, 2013). The mRNA may also mistranslate because of RAN translation to FMRpolyG protein meaning FMRP with a polyglycine tail which is toxic to cells (Sellier et al., 2014, 2017). The second is a co-transcriptional mechanism. Increasing
FMR1 gene transcription links to elevation of R-loop formation and subsequently ineffective clearance of DNA damage repair responses (Loomis et al., 2014). These mechanisms cause mitochondrial dysfunction (Napoli et al., 2011; Song et al., 2016), disrupted intracellular calcium regulation (Robin et al., 2017), and eventually potentiate oxidative stress and inflammatory responses in the cells (Sellier et al., 2014; Hagerman and Hagerman, 2016). Elevated mRNA levels correlated with shorten neuronal survival and abnormal neuronal development in animal models with the FMR1 premutation (Chen et al., 2010; Kaplan et al., 2012). Evidence of RNA toxicity and the sequestration of proteins is displayed as intranuclear inclusions in those with FXTAS which contain mRNA (Tassone et al., 2004) and the sequestered proteins (Iwahashi et al., 2006; Buijsen et al., 2014, 2016; Ma et al., 2019).

Other than in neuronal cells, the inclusions of FXTAS were also found in various organs including subepicardial autonomic ganglia, peripheral nervous system neurons, cardiomyocytes, and mitral valves (Greco et al., 2006; Gokden et al., 2009; Hunsaker et al., 2011; Buijsen et al., 2014) in addition to elevated mRNA levels (Greco et al., 2006; Hunsaker et al., 2011), therefore autonomic dysfunction which includes hypertension

\section{The fragile $X$ premutation}

55-200 CGG repeats on FMR1 gene

- Increase $F M R 1$ transcription

- Decrease translational efficacy

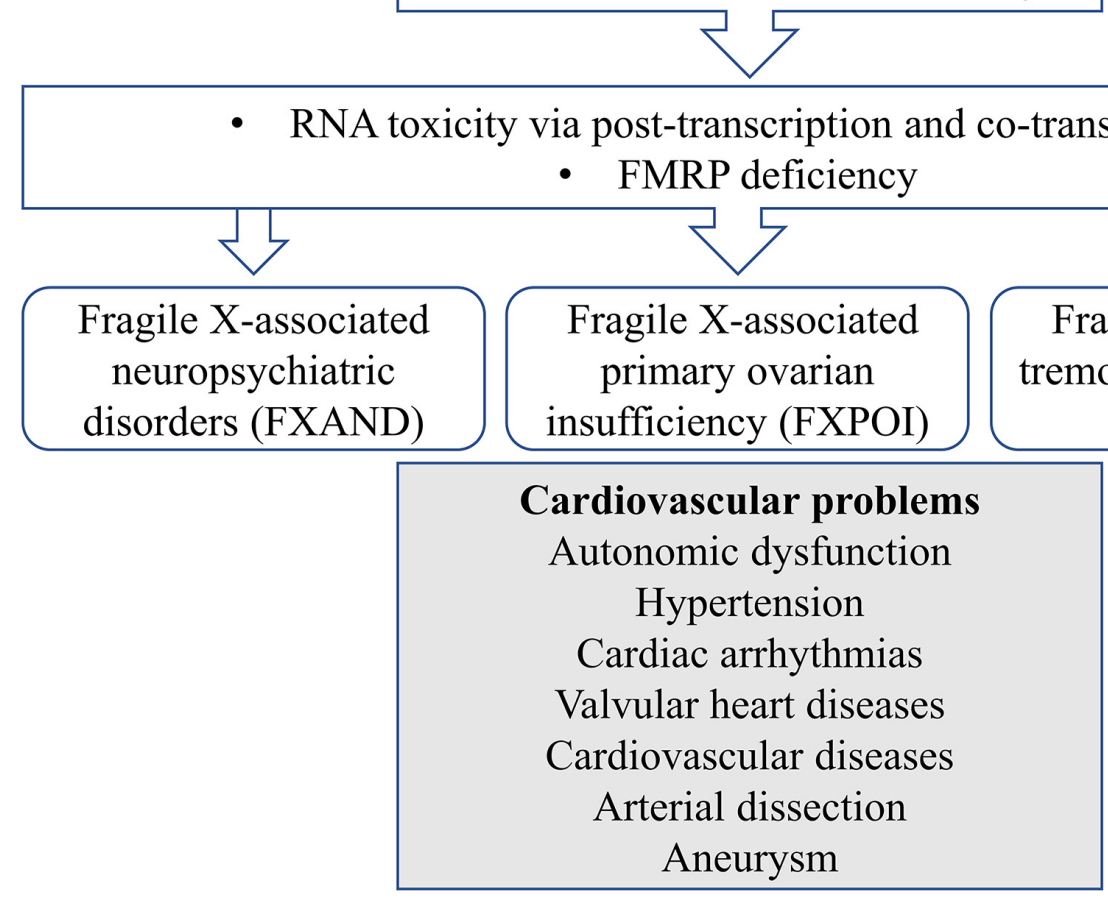

FIGURE 1 | Schematic diagram illustrates mechanisms of cardiovascular problems in the fragile $X$ premutation. 
and cardiac arrhythmia are hypothesized to be a consequence of RNA toxicity. Increasing CGG repeats are also positively correlated with the numbers of inclusions (Greco et al., 2006). Moreover, anatomical and functional changes as well as findings of inclusion bodies in brain areas which regulate autonomic functions also support the hypothesis of RNA toxicity as a mechanism of autonomic dysfunction (Greco et al., 2006; Brown and Stanfield, 2015).

The mechanism of RNA toxicity may partly contribute to the explanation of cardiovascular conditions which link to connective tissue problems; these are arterial dissection (Hayes et al., 2018), aneurysm (Hashimoto et al., 2006; Sadasivan et al., 2013; Yetkin and Ozturk, 2018), and valvular heart disease (El Sabbagh et al., 2018). Increase inflammation and oxidative stress in carriers stimulated by RNA toxicity, have been thought to be an underlying pathophysiology in intracranial aneurysm (Hashimoto et al., 2006; Sadasivan et al., 2013; Yetkin and Ozturk, 2018) and arterial dissection (Hayes et al., 2018).

\section{The Second Mechanism: FMRP Deficiency}

The mechanism might link to cardiovascular problems relate to connective tissue disorder in the carriers. The higher CGG repeats in carriers, especially more than 120 repeats, inversely correlate with FMRP levels (Pretto et al., 2014; Kim et al., 2019) which relates to some characteristics of connective tissue problems such as prominent ears (Riddle et al., 1998), elongated face, and hyperextensible finger joint (Loesch et al., 2003). The impact of FMRP deficiency on connective tissue has been well studied and reviewed in those with FXS (Ramírez-Cheyne et al., 2019). A pathological finding from a male with FXS showed abnormal structure and pattern of elastin, collagen, and acid mucopolysaccharide substrate in tissue samples from aorta, mitral and tricuspid valves, and forearm skin (Waldstein and Hagerman, 1988). From molecular studies, dysregulation of extracellular matrix-related proteins which are regulated by FMRP has been confirmed in FXS. These include matrix metalloproteinases (MMPs), elastin, and actin which are components of connective tissue structure (Ramírez-Cheyne et al., 2019).

The impact of FMRP deficiency on connective tissue in premutation carriers has not been studied. In respect to cardiovascular findings, diminished FMRP might affect endothelial integrity via alteration of MMP-9 expression which is hypothesized as a pathophysiology of dilating arteries (Hashimoto et al., 2006; Dogan et al., 2008; Sadasivan et al., 2013; Yetkin and Ozturk, 2018) and arterial dissection including SCAD (McKenzie et al., 2020). Moreover, the mechanism might lead to less elastic and stiffer vessels especially in those with a high CGG repeat range where FMRP is more deficient (Pretto et al., 2014).

Nonetheless, FMRP levels begin to be lower than average in individuals with a CGG above 120 (Pretto et al., 2014). RNA toxicity may also contribute to the connective tissue problems to some degree as a study found an association between some physical features of connective tissue disorder in the carriers who had normal FMRP level but high mRNA level (Basuta et al., 2011). Furthermore, intranuclear inclusions have been identified in mitral valve tissue from a carrier with mitral regurgitation who had high level of mRNA (Hunsaker et al., 2011). However, it is important to realize that mRNA and FMRP levels were measured in blood samples, so they might not represent actual levels in tissues (Tassone et al., 2000b) and need to be confirmed by direct studies.

\section{Future Directions}

To better understand the risk of having cardiovascular problems in premutation carriers, more direct studies are needed in aspects of prevalence, age of onset, and mechanisms involved. For clinical implications, previous data currently proves that the premutation carriers have high risk of having hypertension (Coffey et al., 2008; Hamlin et al., 2012). Untreated hypertension not only contributes to atherosclerosis, but also causes white matter hyperintensity lesions in the brain which relate to impaired executive function, activities of daily living, gait speed, and mood (Hajjar et al., 2011). Therefore, it is very important to monitor blood pressure and treat as indicated.

In the aspect of cardiovascular diseases, chronic hypoestrogenism in the premutation females with FXPOI probably heightens risk of cardiovascular diseases via various mechanisms particularly atherosclerosis (Morselli et al., 2017). Early detection for FXPOI is crucial and the role of hormonal replacement therapy to reduce risk of having cardiovascular disease needs to be considered (Cobin et al., 2017). Nevertheless, research about the risk of having cardiovascular diseases in the premutation carriers has not been published. Even though ischemic heart disease and congestive heart failure have been reported in individuals with FXTAS (Jacquemont et al., 2003; Greco et al., 2006; Gokden et al., 2009), most of them are males and the mechanism is still unclear. Since FXTAS is associated with increasing mitochondria dysfunction (Napoli et al., 2011; Song et al., 2016), it is likely that end stage FXTAS is associated with such severe mitochondrial dysfunction that the congestive heart failure is also related to the lack of energy from mitochondrial problems (Brown et al., 2017; Zhou and Tian, 2018). Further study to confirm the association is necessary and a treatment for the mitochondrial dysfunction may eventually help myocardial function in aging carriers.

Finally, since neuropsychiatric disorders in carriers called FXAND are very common (Hagerman et al., 2018) and a long history of emotional intensity can lead to enhanced catecholamine release which could aggravate cardiovascular problems including cardiomyopathy (Wittstein et al., 2005), hypertension (Hamlin et al., 2012), and SCAD (McKenzie et al., 2020), therefore, treatment of FXAND should be kept in mind.

\section{CONCLUSION}

The fragile $\mathrm{X}$ premutation carriers are likely to have health conditions throughout their life. This review underscores cardiovascular problems commonly seen in premutation carriers 
and alerts cardiologists and other clinicians to test for the premutation when necessary, watch for these problems and treat the conditions that arise related to the premutation.

\section{DATA AVAILABILITY STATEMENT}

The original contributions presented in the study are included in the article/supplementary material, further inquiries can be directed to the corresponding author/s.

\section{ETHICS STATEMENT}

The studies involving human participants were reviewed and approved by Institutional Review Board at the University of California, Davis. The patients/participants provided their written informed consent to participate in this study. Written informed consent was obtained from the individual(s) for the publication of any potentially identifiable images or data included in this article.

\section{REFERENCES}

Basuta, K., Narcisa, V., Chavez, A., Kumar, M., Gane, L., Hagerman, R., et al. (2011). Clinical phenotypes of a juvenile sibling pair carrying the fragile X premutation. Am. J. Med. Genet. A. 155A, 519-525. doi: 10.1002/ajmg.a.33446

Brown, D. A., Perry, J. B., Allen, M. E., Sabbah, H. N., Stauffer, B. L., Shaikh, S. R., et al. (2017). Mitochondrial function as a therapeutic target in heart failure. Nat. Rev. Cardiol. 14, 238-250. doi: 10.1038/nrcardio.2016.203

Brown, S. S. G., and Stanfield, A. C. (2015). Fragile X premutation carriers: a systematic review of neuroimaging findings. J. Neurol. Sci. 352, 19-28. doi: 10.1016/j.jns.2015.03.031

Buijsen, R. A., Sellier, C., Severijnen, L.-A. W., Oulad-Abdelghani, M., Verhagen, R. F., Berman, R. F., et al. (2014). FMRpolyG-positive inclusions in CNS and non-CNS organs of a fragile $\mathrm{X}$ premutation carrier with fragile $\mathrm{X}$-associated tremor/ataxia syndrome. Acta Neuropathol Commun. 2:162. doi: 10.1186/ s40478-014-0162-2

Buijsen, R. A. M., Visser, J. A., Kramer, P., Severijnen, E. A. W. F. M., Gearing, M., Charlet-Berguerand, N., et al. (2016). Presence of inclusions positive for polyglycine containing protein, FMRpolyG, indicates that repeat-associated non-AUG translation plays a role in fragile $\mathrm{X}$-associated primary ovarian insufficiency. Hum. Reprod. 31, 158-168. doi: 10.1093/humrep/dev280

Campbell, S., Eley, S. E. A., McKechanie, A. G., and Stanfield, A. C. (2016). Endocrine dysfunction in female FMR1 premutation carriers: characteristics and association with ill health. Genes 7:101. doi: 10.3390/genes7110101

Chen, Y., Tassone, F., Berman, R. F., Hagerman, P. J., Hagerman, R. J., Willemsen, R., et al. (2010). Murine hippocampal neurons expressing Fmr1 gene premutations show early developmental deficits and late degeneration. Hum. Mol. Genet. 19, 196-208. doi: 10.1093/hmg/ddp479

Chonchaiya, W., Nguyen, D. V., Au, J., Campos, L., Berry-Kravis, E. M., Lohse, K., et al. (2010). Clinical involvement in daughters of men with fragile $\mathrm{X}$-associated tremor ataxia syndrome. Clin. Genet. 78, 38-46. doi: 10.1111/j.1399-0004.2010. 01448.x

Cobin, R. H., Goodman, N. F., and Aace Reproductive Endocrinology Scientific Committee. (2017). American association of clinical endocrinologists and American college of endocrinology position statement on menopause-2017 update. Endocr. Pract. 23, 869-880. doi: 10.4158/EP171828.PS

Coffey, S. M., Cook, K., Tartaglia, N., Tassone, F., Nguyen, D. V., Pan, R., et al. (2008). Expanded clinical phenotype of women with the FMR1 premutation. Am. J. Med. Genet. A. 146A, 1009-1016. doi: 10.1002/ajmg.a.32060

Dogan, A., Tuzun, N., Turker, Y., Akcay, S., Kaya, S., and Ozaydin, M. (2008). Matrix metalloproteinases and inflammatory markers in coronary artery

\section{AUTHOR CONTRIBUTIONS}

NT, JC, RC, US, and RH discussed the manuscript content. JC, RC, and RH wrote case histories. NT wrote the first draft. All the authors reviewed and edited the manuscript before submission. All authors contributed to the article and approved the submitted version.

\section{FUNDING}

This work was supported by the National Institute of Child Health and Human Development grant R01 HD036071, the Tides Foundation, and the MIND Institute Intellectual and Development Disability Research Centers U54 HD079125.

\section{ACKNOWLEDGMENTS}

We thank Dr. Jordan I. Ziegler who provided imaging information for a case in this manuscript.

ectasia: their relationship to severity of coronary artery ectasia. Coron. Artery. Dis. 19, 559-563. doi: 10.1097/MCA.0b013e3283109079

El Sabbagh, A., Reddy, Y. N. V., and Nishimura, R. A. (2018). Mitral valve regurgitation in the contemporary era: insights into diagnosis, management, and future directions. Cardiovasc. Imaging. 11, 628-643. doi: 10.1016/j.jcmg. 2018.01.009

Garcia-Arocena, D., and Hagerman, P. J. (2010). Advances in understanding the molecular basis of FXTAS. Hum. Mol. Genet. 19, R83-R89. doi: 10.1093/hmg/ ddq166

Gokden, M., Al-Hinti, J. T., and Harik, S. I. (2009). Peripheral nervous system pathology in fragile X tremor/ataxia syndrome (FXTAS). Neuropathology. 29, 280-284. doi: 10.1111/j.1440-1789.2008.00948.x

Greco, C. M., Berman, R. F., Martin, R. M., Tassone, F., Schwartz, P. H., Chang, A., et al. (2006). Neuropathology of fragile X-associated tremor/ataxia syndrome (FXTAS). Brain 129, 243-255. doi: 10.1093/brain/awh683

Hagerman, P. J., and Hagerman, R. J. (2015). Fragile X-associated tremor/ataxia syndrome. Ann. N. Y. Acad. Sci. 1338, 58-70. doi: 10.1111/nyas.12693

Hagerman, R., and Hagerman, P. (2013). Advances in clinical and molecular understanding of the FMR1 premutation and fragile X-associated tremor/ataxia syndrome. Lancet. Neurol. 12, 786-798. doi: 10.1016/S1474-4422(13) 70125-X

Hagerman, R. J., Berry-Kravis, E., Hazlett, H. C., Bailey, D. B. Jr., Moine, H., Kooy, R. F., et al. (2017). Fragile X syndrome. Nat. Rev. Dis. Primers. 3:17065. doi: $10.1038 /$ nrdp. 2017.65

Hagerman, R. J., and Hagerman, P. (2016). Fragile X-associated tremor/ataxia syndrome - features, mechanisms and management. Nat. Rev. Neurol. 12, 403-412. doi: 10.1038/nrneurol.2016.82

Hagerman, R. J., Protic, D., Rajaratnam, A., Salcedo-Arellano, M. J., Aydin, E. Y., and Schneider, A. (2018). Fragile X-associated neuropsychiatric disorders (FXAND). Front. Psychiatry. 9:564. doi: 10.3389/fpsyt.2018.00564

Hajjar, I., Quach, L., Yang, F., Chaves, P. H. M., Newman, A. B., Mukamal, K., et al. (2011). Hypertension, white matter hyperintensities and concurrent impairments in mobility, cognition and mood: the cardiovascular health study. Circulation 123, 858-865. doi: 10.1161/CIRCULATIONAHA.110.978114

Hamlin, A. A., Sukharev, D., Campos, L., Mu, Y., Tassone, F., Hessl, D., et al. (2012). Hypertension in FMR1 premutation males with and without fragile $\mathrm{X}$-associated tremor/ataxia syndrome (FXTAS). Am. J. Med. Genet. A. 158A, 1304-1309. doi: 10.1002/ajmg.a.35323

Hashimoto, T., Meng, H., and Young, W. L. (2006). Intracranial aneurysms: links among inflammation, hemodynamics and vascular remodeling. Neurol. Res. 28, 372-380. doi: 10.1179/016164106X14973 
Hayes, S. N., Kim, E. S. H., Saw, J., Adlam, D., Arslanian-Engoren, C., Economy, K. E., et al. (2018). Spontaneous coronary artery dissection: current state of the science: a scientific statement from the American heart association. Circulation 137, e523-e557. doi: 10.1161/CIR.0000000000000564

Hunsaker, M. R., Greco, C. M., Spath, M. A., Smits, A. P. T., Navarro, C. S., Tassone, F., et al. (2011). Widespread non-central nervous system organ pathology in fragile X premutation carriers with fragile X-associated tremor/ataxia syndrome and CGG knock-in mice. Acta. Neuropathol. 122, 467-479. doi: 10.1007/ s00401-011-0860-9

Iwahashi, C. K., Yasui, D. H., An, H.-J., Greco, C. M., Tassone, F., Nannen, K., et al. (2006). Protein composition of the intranuclear inclusions of FXTAS. Brain 129, 256-271. doi: 10.1093/brain/awh650

Jacquemont, S., Hagerman, R. J., Leehey, M., Grigsby, J., Zhang, L., Brunberg, J. A., et al. (2003). Fragile X premutation tremor/ataxia syndrome: molecular, clinical, and neuroimaging correlates. Am. J. Hum. Genet. 72, 869-878. doi: $10.1086 / 374321$

Jacquemont, S., Hagerman, R. J., Leehey, M. A., Hall, D. A., Levine, R. A., Brunberg, J. A., et al. (2004). Penetrance of the fragile X-associated tremor/ataxia syndrome in a premutation carrier population. JAMA 291, 460-469. doi: 10. 1001/jama.291.4.460

Kaplan, E. S., Cao, Z., Hulsizer, S., Tassone, F., Berman, R. F., Hagerman, P. J., et al. (2012). Early mitochondrial abnormalities in hippocampal neurons cultured from Fmr1 premutation mouse model. J. Neurochem. 123, 613-621. doi: 10. 1111/j.1471-4159.2012.07936.x

Kenneson, A., Zhang, F., Hagedorn, C. H., and Warren, S. T. (2001). Reduced FMRP and increased FMR1 transcription is proportionally associated with CGG repeat number in intermediate-length and premutation carriers. Hum. Mol. Genet. 10, 1449-1454. doi: 10.1093/hmg/10.14.1449

Kim, K., Hessl, D., Randol, J. L., Espinal, G. M., Schneider, A., Protic, D., et al. (2019). Association between IQ and FMR1 protein (FMRP) across the spectrum of CGG repeat expansions. PLoS. One 14:e0226811. doi: 10.1371/journal.pone. 0226811

Klusek, J., LaFauci, G., Adayev, T., Brown, W. T., Tassone, F., and Roberts, J. E. (2017). Reduced vagal tone in women with the FMR1 premutation is associated with FMR1 mRNA but not depression or anxiety. J. Neurodev. Disord. 9:16. doi: 10.1186/s11689-017-9197-6

Leehey, M. A. (2009). Fragile X-associated tremor/ataxia syndrome: clinical phenotype, diagnosis, and treatment. J. Investig. Med. 57, 830-836. doi: 10.2310/ JIM.0b013e3181af59c4

Loehr, J. P., Synhorst, D. P., Wolfe, R. R., and Hagerman, R. J. (1986). Aortic root dilatation and mitral valve prolapse in the fragile $\mathrm{X}$ syndrome. Am. J. Med. Genet. 23, 189-194. doi: 10.1002/ajmg.1320230113

Loesch, D. Z., Huggins, R. M., Bui, Q. M., Taylor, A. K., and Hagerman, R. J. (2003). Relationship of deficits of FMR1 gene specific protein with physical phenotype of fragile X males and females in pedigrees: a new perspective. Am. J. Med. Genet. A. 118A, 127-134. doi: 10.1002/ajmg.a.10099

Loomis, E. W., Sanz, L. A., Chédin, F., and Hagerman, P. J. (2014). Transcriptionassociated R-Loop formation across the human FMR1 CGG-repeat region. PLoS. Genet. 10:e1004294. doi: 10.1371/journal.pgen.1004294

Ma, L., Herren, A. W., Espinal, G., Randol, J., McLaughlin, B., MartinezCerdeno, V., et al. (2019). Composition of the intranuclear inclusions of fragile $\mathrm{X}$-associated tremor/ataxia syndrome. Acta Neuropathol. Commun. 7:143. doi: 10.1186/s40478-019-0796-1

McKenzie, F. J., Tassankijpanich, N., Epps, K. C., March, S. K., and Hagerman, R. J. (2020). Spontaneous coronary artery dissection in females with the fragile X FMR1 premutation. JACC Case. Rep. 2, 40-44. doi: 10.1016/j.jaccas.2019. 11.058

Morselli, E., Santos, R. S., Criollo, A., Nelson, M. D., Palmer, B. F., and Clegg, D. J. (2017). The effects of oestrogens and their receptors on cardiometabolic health. Nat. Rev. Endocrinol. 13, 352-364. doi: 10.1038/nrendo.2017.12

Napoli, E., Ross-Inta, C., Wong, S., Omanska-Klusek, A., Barrow, C., Iwahashi, C., et al. (2011). Altered zinc transport disrupts mitochondrial protein processing/import in fragile X-associated tremor/ataxia syndrome. Hum. Mol. Genet. 20, 3079-3092. doi: 10.1093/hmg/ddr211

Park, H.-Y., Cho, J.-M., Kim, D.-H., Park, C.-B., and Kim, C.-J. (2017). Spontaneous coronary artery dissection in a female patient with fragile X syndrome. Kosin. Med. J. 32, 240-243. doi: 10.7180/kmj.2017.32. 2.240
Pretto, D. I., Mendoza-Morales, G., Lo, J., Cao, R., Hadd, A., Latham, G. J., et al. (2014). CGG allele size somatic mosaicism and methylation in FMR1 premutation alleles. J. Med. Genet. 51, 309-318. doi: 10.1136/jmedgenet-2013102021

Pugliese, P., Annesi, G., Cutuli, N., Arabia, G., Nicoletti, G., Annesi, F., et al. (2004). The fragile $\mathrm{X}$ premutation presenting as postprandial hypotension. Neurology 63, 2188-2189. doi: 10.1212/01.wnl.0000145709.61117.08

Rajaratnam, A., Shergill, J., Salcedo-Arellano, M., Saldarriaga, W., Duan, X., and Hagerman, R. (2017). Fragile X syndrome and fragile X-associated disorders. F1000Res 6:2112. doi: 10.12688/f1000research.11885.1

Ramírez-Cheyne, J. A., Duque, G. A., Ayala-Zapata, S., Saldarriaga-Gil, W., Hagerman, P., Hagerman, R., et al. (2019). Fragile X syndrome and connective tissue dysregulation. Clin. Genet. 95, 262-267. doi: 10.1111/cge.13469

Riddle, J. E., Cheema, A., Sobesky, W. E., Gardner, S. C., Taylor, A. K., Pennington, B. F., et al. (1998). Phenotypic involvement in females with the FMR1 gene mutation. Am. J. Ment. Retard. 102, 590-601. doi: 10.1352/089580171998102(0590:piifwt(2.0.co;2

Robin, G., López, J. R., Espinal, G. M., Hulsizer, S., Hagerman, P. J., and Pessah, I. N. (2017). Calcium dysregulation and Cdk5-ATM pathway involved in a mouse model of fragile X-associated tremor/ataxia syndrome. Hum. Mol. Genet. 26, 2649-2666. doi: 10.1093/hmg/ddx148

Sadasivan, C., Fiorella, D. J., Woo, H. H., and Lieber, B. B. (2013). Physical factors effecting cerebral aneurysm pathophysiology. Ann. Biomed. Eng. 41, 1347-1365. doi: 10.1007/s10439-013-0800-z

Sellier, C., Buijsen, R. A. M., He, F., Natla, S., Jung, L., Tropel, P., et al. (2017). Translation of expanded CGG repeats into FMRpolyG is pathogenic and may contribute to fragile X tremor ataxia syndrome. Neuron 93, 331-347. doi: 10. 1016/j.neuron.2016.12.016

Sellier, C., Freyermuth, F., Tabet, R., Tran, T., He, F., Ruffenach, F., et al. (2013). Sequestration of DROSHA and DGCR8 by expanded CGG RNA repeats alters microRNA processing in fragile X-associated tremor/ataxia Syndrome. Cell. Rep. 3, 869-880. doi: 10.1016/j.celrep.2013.02.004

Sellier, C., Rau, F., Liu, Y., Tassone, F., Hukema, R. K., Gattoni, R., et al. (2010). Sam68 sequestration and partial loss of function are associated with splicing alterations in FXTAS patients. EMBO. J. 29, 1248-1261. doi: 10.1038/emboj. 2010.21

Sellier, C., Usdin, K., Pastori, C., Peschansky, V. J., Tassone, F., and CharletBerguerand, N. (2014). The multiple molecular facets of fragile X-associated tremor/ataxia syndrome. J. Neurodev. Disord. 6:23. doi: 10.1186/18661955-6-23

Song, G., Napoli, E., Wong, S., Hagerman, R., Liu, S., Tassone, F., et al. (2016). Altered redox mitochondrial biology in the neurodegenerative disorder fragile $\mathrm{X}$-tremor/ataxia syndrome: use of antioxidants in precision medicine. Mol. Med. 22, 548-559. doi: 10.2119/molmed.2016.00122

Sreeram, N., Wren, C., Bhate, M., Robertson, P., and Hunter, S. (1989). Cardiac abnormalities in the fragile X syndrome. Br. Heart. J. 61, 289-291. doi: 10.1136/ hrt.61.3.289

Tassone, F., Beilina, A., Carosi, C., Albertosi, S., Bagni, C., Li, L., et al. (2007). Elevated FMR1 mRNA in premutation carriers is due to increased transcription. RNA 2007, 555-562. doi: 10.1261/rna.280807

Tassone, F., Greco, C. M., Hunsaker, M. R., Seritan, A. L., Berman, R. F., Gane, L. W., et al. (2012a). Neuropathological, clinical and molecular pathology in female fragile X premutation carriers with and without FXTAS. Genes. Brain. Behav. 11, 577-585. doi: 10.1111/j.1601-183X.2012.00779.x

Tassone, F., Hagerman, R. J., Taylor, A. K., Gane, L. W., Godfrey, T. E., and Hagerman, P. J. (2000a). Elevated levels of FMR1 mRNA in carrier males: a new mechanism of involvement in the fragile-X syndrome. Am. J. Hum. Genet. 66, 6-15. doi: 10.1086/302720

Tassone, F., Hagerman, R. J., Taylor, A. K., Mills, J. B., Harris, S. W., Gane, L. W., et al. (2000b). Clinical involvement and protein expression in individuals with the FMR1 premutation. Am. J. Med. Genet. 91, 144-152. doi: 10.1002/(sici) 1096-8628(20000313)91:2(144:aid-ajmg14(3.0.co;2-v

Tassone, F., Iong, K. P., Tong, T.-H., Lo, J., Gane, L. W., Berry-Kravis, E., et al. (2012b). FMR1 CGG allele size and prevalence ascertained through newborn screening in the United States. Genome. Med. 4, 100. doi: 10.1186/gm401

Tassone, F., Iwahashi, C., and Hagerman, P. J. (2004). FMR1 RNA within the intranuclear inclusions of fragile $\mathrm{X}$-associated tremor/ataxia syndrome (FXTAS). RNA Biol. 1, 103-105. doi: 10.4161/rna.1.2.1035 
Utari, A., Adams, E., Berry-Kravis, E., Chavez, A., Scaggs, F., Ngotran, L., et al. (2010). Aging in fragile X syndrome. J. Neurodev. Disord. 2, 70-76. doi: 10.1007/ s11689-010-9047-2

Waldstein, G., and Hagerman, R. (1988). Aortic hypoplasia and cardiac valvular abnormalities in a boy with fragile X syndrome. Am. J. Med. Genet. 30, 83-98. doi: 10.1002/ajmg.1320300107

Wheeler, A. C., Bailey, D. B., Berry-Kravis, E., Greenberg, J., Losh, M., Mailick, M., et al. (2014). Associated features in females with an FMR1 premutation. J. Neurodev. Disord. 6:30. doi: 10.1186/1866-1955-6-30

Winarni, T. I., Chonchaiya, W., Sumekar, T. A., Ashwood, P., Morales, G. M., Tassone, F., et al. (2012). Immune-mediated disorders among women carriers of fragile X premutation alleles. Am. J. Med. Genet. A. 158A, 2473-2481. doi: 10.1002/ajmg.a.35569

Wittstein, I. S., Thiemann, D. R., Lima, J. A. C., Baughman, K. L., Schulman, S. P., Gerstenblith, G., et al. (2005). Neurohumoral features of myocardial stunning due to sudden emotional stress. N. Engl. J. Med. 352, 539-548. doi: 10.1056/ NEJMoa043046

Yetkin, E., and Ozturk, S. (2018). Dilating vascular diseases: pathophysiology and clinical aspects. Int. J. Vasc. Med. 2018:9024278. doi: 10.1155/2018/9024278
Zhou, B., and Tian, R. (2018). Mitochondrial dysfunction in pathophysiology of heart failure. J. Clin. Invest. 128, 3716-3726. doi: 10.1172/JCI120849

Conflict of Interest: RH has consulted with Zynerba and Fulcrum regarding treatment of Fragile $\mathrm{X}$ syndrome and she has received funding from the Azrieli Foundation, Ovid, and Zynerba to carry out treatment studies in Fragile $\mathrm{X}$ syndrome.

The remaining authors declare that the research was conducted in the absence of any commercial or financial relationships that could be construed as a potential conflict of interest.

Copyright ( $\odot 2020$ Tassanakijpanich, Cohen, Cohen, Srivatsa and Hagerman. This is an open-access article distributed under the terms of the Creative Commons Attribution License (CC BY). The use, distribution or reproduction in other forums is permitted, provided the original author(s) and the copyright owner(s) are credited and that the original publication in this journal is cited, in accordance with accepted academic practice. No use, distribution or reproduction is permitted which does not comply with these terms. 